\title{
A RELAÇÃO ENTRE MATERIALIDADE E IMATERIALIDADE NA SALVAGUARDA DOS PATRIMONIOS CULTURAIS IMATERIAIS: uma análise a partir da Roda de Capoeira ${ }^{1}$
}

\section{THE RELATIONSHIP BETWEEN MATERIALITY AND IMMATERIALITY IN SAFEGUARDING INTANGIBLE CULTURAL HERITAGE: an analysis from the Roda de Capoeira}

\author{
LA RELACIÓN ENTRE MATERIALIDAD E INMATERIALIDAD EN LA \\ SALVAGUARDIA DEL PATRIMONIO CULTURAL INMATERIAL: \\ un análisis desde la Roda de Capoeira
}

Andressa Marques Siqueira

Doutora em Ciência Ambiental

Universidade de São Paulo andressa.siqueira@alumni.usp.br

Brasil

ORCID 0000-0001-8061-523X

\section{Resumo}

O presente artigo analisa a salvaguarda da Roda de Capoeira, bem cultural registrado como Patrimônio Cultural Imaterial do Brasil e da Humanidade, sob o aspecto da interação entre materialidade e imaterialidade e seus elementos emergentes. Considera que a cultura imaterial tem como base de sustentação aspectos materiais que não poder ser desconsiderados e que a efetiva salvaguarda do patrimônio cultural imaterial demanda abordagens e ações que estão além do universo do intangível. Por meio de pesquisa bibliográfica, documental, e observação participante, o artigo revela que a salvaguarda da Roda de Capoeira ressalta a importância da conservação do berimbau como elemento material essencial à prática da expressão cultural e destaca o uso de bens naturais como ação componente dessa materialidade. Demonstra que riscos relacionados à possibilidade de

\footnotetext{
${ }^{1}$ Paper originalmente apresentado no Grupo de Trabalho 20, intitulado «Salvaguarda do patrimônio cultural e dos direitos identitários », do VI ENADIR (Encontro Nacional de Antropologia do Direito), ocorrido entre 26 e 29 de agosto de 2019 na FFLCH-USP (Faculdade de Filosofia, Letras e Ciências Humanas da Universidade de São Paulo).
} 
uso desses bens naturais, como a escassez ou a falta de acesso aos mesmos, representam também riscos à salvaguarda da base material de suporte e, consequentemente, da salvaguarda desse patrimônio. Conclui que a ação política para a salvaguarda do bem imaterial, nesse caso, deve considerar o direito dos detentores culturais aos bens naturais que são parte da expressão cultural.

Palavras-chave: Patrimônio Cultural, salvaguarda, imaterialidade, Capoeira.

\section{Abstract}

This article analyzes the safeguarding of Roda de Capoeira, a cultural asset registered as Intangible Cultural Heritage of Brazil and Humanity, under the aspect of the interaction between materiality and immateriality and its emerging elements. It considers that immaterial culture is based on material aspects that cannot be disregarded and that the effective safeguarding of intangible cultural heritage requires approaches and actions that are beyond the universe of the intangible. Through bibliographical and documentary research, and participant observation, the article reveals that the safeguarding of the Roda de Capoeira shows the importance of the conservation of berimbau as an essential material element for the practice of cultural expression and highlights the use of natural goods as an action component of this materiality. It demonstrates that risks related to the possibility of using these natural assets, such as scarcity or lack of access to them, also represent risks for safeguarding the material support base and, consequently, for safeguarding this heritage. It concludes that political action to safeguard the immaterial heritage, in this case, must consider the right of cultural holders to natural assets that are part of cultural expression.

Keywords: Cultural Heritage, safeguard, immateriality, Capoeira.

\section{Resumen}

Este artículo analiza la salvaguarda de la Roda de Capoeira, bien cultural inscrito como Patrimonio Cultural Inmaterial de Brasil y la Humanidad, bajo el aspecto de la interacción entre la materialidad y la inmaterialidad y sus elementos emergentes. Considera que la cultura inmaterial se basa en aspectos materiales que no pueden ser ignorados y que la salvaguarda efectiva del patrimonio cultural inmaterial requiere enfoques y acciones que van más allá del universo de lo inmaterial. A través de la investigación bibliográfica, documental y la observación participante, el artículo revela que la salvaguarda de la Roda de Capoeira destaca la importancia de la conservación del berimbau como elemento material esencial para la práctica de la expresión cultural y destaca el uso de bienes naturales como componente de esta materialidade. Demuestra que los riesgos relacionados con la posibilidad de uso de estos bienes naturales, como la escasez o la falta de acceso a los mismos, también representan riesgos para salvaguardar la base de sustento material y, en consecuencia, para salvaguardar este patrimonio. Concluye que la acción política para salvaguardar el bien inmaterial, en este caso, debe considerar el derecho de los poseedores culturales a los bienes naturales que forman parte de la expresión cultural.

Palabras clave: Patrimonio cultural, salvaguardia, inmaterialidad, Capoeira. 
A Capoeira é uma manifestação cultural de características múltiplas, sendo ao mesmo tempo luta, dança e jogo. Está presente em todo o Brasil e também nos cinco continentes, podendo ser observada em mais de 150 países (IPHAN, 2014). De acordo com autores como Waldeloir Rego (1968), Almir das Areias (1983), dentre outros, a Capoeira tem sua gênese no Brasil, tendo expressões culturais africanas como matrizes.

No ano de 2008 a Capoeira foi reconhecida como Patrimônio Cultural Imaterial do Brasil quando a Roda de Capoeira foi registrada no Livro de Registro das Formas de Expressão e o Ofício dos Mestres de Capoeira no Livro de Registro dos Saberes. No ano de 2014, a Roda de Capoeira foi também reconhecida com Patrimônio Cultural Imaterial da Humanidade.

O processo de ativação patrimonial da Capoeira envolveu diversas ações sendo destaque a elaboração do Inventário e do Plano de Salvaguarda do bem cultural. Conforme preconiza o Decreto $\mathrm{N}^{\mathrm{o}} 3.551$, de 4 de agosto de 2000, todo bem cultural registrado é precedido de um inventário e sucedido de um Plano de Salvaguarda.

Nesses documentos, o berimbau, instrumento musical símbolo da prática cultural, teve sua sustentabilidade como condicionante da salvaguarda do bem cultural, o que relacionou a conservação do patrimônio cultural imaterial a um elemento material e revelou a temática ambiental como elemento emergente dessa interação, uma vez que a produção do instrumento demanda a apropriação de bens naturais.

\section{Considerando esse cenário, o} presente artigo aborda a salvaguarda dos Patrimônios Culturais Imateriais no que tange à relação entre materialidade e imaterialidade e seus elementos emergentes. Para tal, toma o processo de ativação patrimonial e a salvaguarda da Roda de Capoeira como foco de análise.

Inicialmente o artigo apresenta a relação entre materialidade e imaterialidade no âmbito dos patrimônios culturais $\mathrm{e}$ ressalta a dicotomia entre material e imaterial como algo a ser superado nas ações de salvaguarda do patrimônio cultural imaterial. Em seguida, aborda o processo de ativação patrimonial da Roda de Capoeira e as recomendações de salvaguarda, com destaque para o berimbau como elemento material condicionante da salvaguarda do bem cultural, e para o uso cultural de bens naturais como ação componente dessa materialidade. Por fim, apresenta que os planos e ações destinadas à salvaguarda da Roda de Capoeira demandam a contemplação dos elementos materiais que a suportam e necessitam abordar a temática ambiental, incluindo o direito dos 
detentores culturais ao uso cultural de bens naturais relacionados a essa base material.

\section{As dimensões material e}

\section{imaterial na salvaguarda dos patrimônios culturais imateriais}

No Brasil, o aspecto imaterial da cultura como assunto de interesse nacional foi reconhecido no ano 1988, por meio da sua Constituição Federal, na qual o Artigo 215 estabeleceu a proteção do Estado às manifestações das culturas populares e o Artigo 216 definiu o patrimônio cultural brasileiro como:

Art. 216. Constituem patrimônio cultural brasileiro os bens de natureza material e imaterial, tomados individualmente ou em conjunto, portadores de referência à identidade, à ação, à memória dos diferentes grupos formadores da sociedade brasileira, nos quais se incluem:

I. as formas de expressão;

II. os modos de criar, fazer e viver;

III. as criações científicas, artísticas e tecnológicas;

IV. as obras, objetos, documentos, edificações e demais espaços destinados às manifestações artísticas;

V. os conjuntos urbanos e sítios de valor histórico, paisagístico, artístico, arqueológico, paleontológico, ecológico e cientifico.

Parágrafo 1. O poder público, com a colaboração da comunidade, promoverá e protegerá o patrimônio cultural brasileiro por meio de inventários, registros, vigilância, tombamento e desapropriação, e de outras formas de acautelamento e preservação. (BRASIL, 1988, Art.216)

A conceituação de patrimônio cultural presente no artigo exposto permite analisar que o mesmo é definido de acordo com a lógica binária de separação entre material e imaterial. Assim, trata o tema de forma não dialógica, considerando oposições e não associações.

Na prática, ao se pensar a gestão dos patrimônios culturais sob essa conceituação, tem-se as oposições como um problema porque a cultura não se expressa em categorias estanques, mas compõe uma rede de significados (GEERTZ, 1989) e cada vez que o ser humano interage com a materialidade estamos diante de uma realidade híbrida (RAYNAUT, 2015). Desta forma, a conceituação de patrimônio cultural embasada na separação de material e imaterial é algo que demanda questionamento.

Esse questionamento tem sido realizado por diversos autores e estudiosos do tema que oscilam entre a melhor maneira de definir a cultura dos saberes e fazeres, que chamamos de "imaterial" e diferencialas da cultura representada pelas edificações e objetos, que denominamos "material".

José Newton Coelho Meneses (2009) ressalta que “intangível" e 
"imaterial" são vocábulos que parecem denotar o patrimônio não materializável, mas que, na verdade, não o faz, pois os saberes, de maneira geral, conjugam materialidade e imaterialidades. $\mathrm{O}$ autor ressalta que a expressão "patrimônio imaterial" e o termo imaterialidade parecem inconsistentes para adjetivar práticas, fazeres e saberes, pois o valor dos instrumentos e dos saberes, das matériasprimas e das técnicas, do produto e dos seus significados formam uma unidade complexa, que vai além da imaterialidade. Para o autor, essa inconsistência tem origem na opção didática de contraposição dicotômica, herdeira de uma tradição que opõe o natural e o cultural nas discussões sobre a cultura.

Simone Toji (2009) destaca que as denominações "material" e "imaterial” são muito mais um posicionamento de práticas consolidadas por parte dos órgãos de patrimônio, do que categorias coerentes para designar os bens culturais, pois os bens culturais de natureza imaterial só podem se realizar mediante suportes materiais.

Na mesma linha, Maria Cecília Londres Fonseca (2000), Márcia Sant'Anna (2003), Dominique Gallois (2006) e María Pia Tiemblo (2013) têm claro que é impossível separar o material a partir do imaterial no contexto da cultura. O material é concebido como um suporte físico "culturizado" no qual repousam os significados e informações, que é o que chamamos de cultura imaterial; e o imaterial não existe de forma independente, mas sim em função dos referenciais materiais.

Construções e objetos como, por exemplo, igrejas e obras de arte, são considerados patrimônios, diferenciados de outras construções e objetos, por seu caráter intangível, pelos significados que adquirem socialmente e não pelo componente físico em si. Da mesma forma, os bens imateriais estão necessariamente imbricados em um universo material que lhes dá suporte.

Tendo como foco a dicotomia entre material e imaterial no campo do patrimônio, o que se observa é que essa separação é uma construção discursiva que não se sustenta na relação da sociedade com os seus bens culturais (SOUZA; CRIPPA, 2011), tanto que as resoluções recentes da UNESCO e de alguns Estados nacionais têm reafirmado a inter-relação entre materialidade e imaterialidade.

A definição de patrimônio cultural imaterial presente na Convenção para a Salvaguarda do Patrimônio Cultural Imaterial da UNESCO reconhece a relação entre os aspectos imaterial e material, quando apresenta o intangível - práticas, representações, expressões, conhecimentos e técnicas; em conjunto com o tangível - 
instrumentos, objetos, artefatos e lugares culturais associados.

[...] Entende-se por "patrimônio cultural imaterial" as práticas, representações, expressões, conhecimentos e técnicas - junto com os instrumentos, objetos, artefatos e lugares culturais que lhes são associados - que as comunidades, os grupos e, em alguns casos, os indivíduos reconhecem como parte integrante de seu patrimônio cultural. (UNESCO, 2003, Art.2, 1).

\section{Corroborando}

com

os

direcionamentos e indicativos da UNESCO, nos dispositivos do IPHAN que tem o foco na salvaguarda dos patrimônios culturais imateriais, se observa que a materialidade dos bens imateriais é considerada um elemento importante. A instituição trabalha com a afirmativa de que preservação desses patrimônios passa pelo acesso às matérias primas e insumos necessários à sua produção. O que se entende é que a preservação tem como foco "a busca de instrumentos e medidas de salvaguarda que viabilizem as condições de sua produção e reprodução, tais como: o acesso às matérias primas e demais insumos necessários à sua produção" (IPHAN, 2010, p.18).

No entanto, ao debater o patrimônio cultural imaterial e sua conservação, o IPHAN considera o acesso às matériasprimas, mas não toca no compromisso de encontrar meios para a conservação dos suportes físicos dos bens. Isso mostra que a relação entre material e imaterial é observada, mas os direcionamentos nas ações de salvaguarda, grosso modo, não se voltam para a conservação dos suportes materiais.

Na prática, o que se tem na estrutura do IPHAN são departamentos separados por tratativas do patrimônio material e imaterial que, normalmente, não atuam em conjunto. A atuação do Departamento de Patrimônio Imaterial (DPI/IPHAN) se circunscreve ao intangível.

No âmbito das regulamentações, não há direcionamentos ou instruções formais no IPHAN para a abordagem dos aspectos materiais na salvaguarda dos patrimônios culturais imateriais. A contemplação desses aspectos fica a mercê da temática se apresentar como um problema a ser pensado, e as resoluções se dão caso a caso.

Considerando a indissolução entre materialidade e imaterialidade no âmbito dos patrimônios culturais e sua salvaguarda, bem como as observações de que a estrutura do IPHAN não colabora na integração dos aspectos materiais e imateriais na gestão do patrimônio cultural imaterial, o artigo apresenta a salvaguarda da Roda de Capoeira como objeto de análise da relação entre materialidade e imaterialidade na salvaguarda dos patrimônios culturais imateriais. 


\section{A materialidade como condicionante da salvaguarda da Roda de Capoeira}

A Capoeira é uma manifestação cultural de características múltiplas, sendo ao mesmo tempo luta, dança e jogo. Dentre seus componentes, a Roda de Capoeira foi a expressão registrada como patrimônio cultural imaterial por ser integradora de todos os elementos, uma vez que combina música, luta/jogo e dança e carrega uma série de significados simbólicos e mítico-religiosos.

Sobre a Roda de Capoeira, IPHAN afirma que "é preciso admitir que a roda de capoeira, como hoje a conhecemos, perde o sentido sem a utilização do elemento música e dos objetos musicais que a constituem" (IPHAN, 2014, p.103). Essa afirmativa ressalta não apenas a música como elemento essencial a pratica cultural, mas também os "objetos musicais" utilizados na Roda de Capoeira como componentes de destaque. Esses "objetos" configuram a base material de suporte da Roda de Capoeira como bem imaterial, sem a qual a expressão cultural "perde o sentido" e, dentre eles, estão os instrumentos: berimbau, atabaque, pandeiro, reco-reco e agogô, cuja utilização varia de acordo com o estilo de capoeira a ser praticado.

Considerando a importância desses elementos materiais para prática cultural e para seu sentido, a salvaguarda da Roda de Capoeira necessita avaliar em que medida essa base material foi considerada no processo de ativação patrimonial do bem cultural que o elevou a condição de patrimônio cultural imaterial. Mais especificamente, é necessário identificar se a base material da Roda de Capoeira e sua conservação foram contempladas nos instrumentais componentes do processo. Para tal, tem-se que os direcionamentos e ações de salvaguarda de um bem cultural imaterial são definidos ao longo de todo o processo de ativação patrimonial, que vai desde o inventário até a elaboração e execução do Plano de Salvaguarda do bem cultural.

No caso da Roda Capoeira, as ações de salvaguarda do bem cultural começaram a ser definidas antes da solicitação do registro do bem cultural, quando algumas ações e políticas voltadas à valorização e conservação da expressão cultural já estavam em andamento. Dentre elas, destaque deve ser dado ao lançamento do Programa Nacional e Mundial para Capoeira, feito pelo ministro Gilberto Gil no evento em homenagem a Sérgio Vieira de Mello, realizado na sede da ONU em Genebra, em 19 de agosto de 2004.

Nesse programa, o ministro apontou de antemão projetos e ações destinados à salvaguarda da expressão cultural. Esses apontamentos serviram de linha condutora 
ao processo de ativação patrimonial e se referiram, principalmente, à valorização dos saberes dos mestres e reconhecimento da expressão cultural como instrumento de educação e cidadania.

Ainda antes da ativação patrimonial da Roda de Capoeira e também como ação relacionada à sua salvaguarda, seguiu-se o lançamento, em 2006, do Programa Capoeira Viva, que contou com duas edições financiadas pela Petrobras, sendo o primeiro edital do ano de 2006 e o segundo de 2007. Esse programa tinha o objetivo de apoiar projetos voltados à documentação e pesquisa da Capoeira, além da execução de ações socioeducativas com foco na expressão cultural.

Em paralelo ao Programa Capoeira Viva, e já diretamente relacionado ao processo de ativação patrimonial, nos anos de 2006 e 2007 foram realizados os estudos para o inventário da Roda de Capoeira, considerado pelo IPHAN um dos instrumentos básicos de salvaguarda dos patrimônios imateriais.

É a partir desse momento que os capoeiristas se envolvem com o processo de ativação patrimonial e que a base material da expressão cultural tem destaque quando acontecem os encontros "Capoeira como

\footnotetext{
2 Biriba é o nome popular da espécie Eschweilera ovata (Cambess.) Mart. ex Miers, bem natural mais utilizado na produção do berimbau.
}

Patrimônio Imaterial do Brasil", nas cidades do Rio de Janeiro, Salvador e Pernambuco. Esses encontros tiveram a participação de mestres, alunos e pesquisadores, e o objetivo de discutir a importância do inventário, definir as possibilidades de registro e fazer um levantamento de pautas que seriam utilizadas como referências para a elaboração das recomendações do plano de salvaguarda (IPHAN, 2014). Nesses encontros foi revelada a preocupação dos capoeiristas com a sustentabilidade do berimbau, instrumento musical símbolo da capoeira e, dentre os direcionamentos de salvaguarda foi apontada a necessidade de um "plano de manejo da biriba",", o que revelou também a possível escassez da biriba como bem natural utilizado na produção do berimbau.

De acordo com o Decreto $N^{\circ} 3.551$, de 4 de agosto de 2000, o Inventário Nacional de Referências Culturais (INRC) é o documento que contem todo detalhamento da cultura a ser patrimonializada, bem como o apontamento dos riscos e ameaças à conservação do patrimônio, além dos direcionamentos para salvaguarda desse patrimônio. Portanto, se a base material de um bem intangível é essencial à sua manutenção, o documento deve abordá-la. 
O inventário da Roda de Capoeira apresenta inicialmente os aspectos históricos, desde os mitos fundadores até o processo de transformação em desporto; as Rodas de Capoeira em descrição etnográfica, de performance, golpes e dinâmica musical; cita os instrumentos utilizados e reconhece a interação entre os mestres e as Rodas de Capoeira enquanto "patrimônio vivo". Por fim, apresenta as recomendações destinadas à salvaguarda e difusão da Capoeira.

Dentre essas recomendações, o inventário apresenta a materialidade como condicionante da salvaguarda do bem imaterial quando traz a necessidade de um "plano de manejo da biriba e outros recursos", em atendimento a demanda dos capoeiristas, oriunda dos encontros previamente realizados que apontaram a importância da sustentabilidade do instrumento berimbau em decorrência da escassez da espécie biriba, principal bem natural utilizado na produção do instrumento.

No documento, o IPHAN enfatiza a produção do berimbau e cita o extrativismo como forma de obtenção da biriba e outros bens naturais utilizados na produção do instrumento. Relaciona não apenas 0 berimbau como elemento material condicionante da salvaguarda do bem imaterial, mas traz a temática ambiental no rol dessa condicionante, pois no que se refere especificamente ao berimbau e a espécie biriba, o documento aborda o problema de acesso ao bem natural, destacando que ele encontra-se em condição de escassez.

Observando os direcionamentos de salvaguarda das ações pré-inventario e do inventário propriamente dito, se observa que a relação entre materialidade e imaterialidade foi percebida pela comunidade detentora e ratificada pelo IPHAN, pois o inventário destacou a sustentabilidade do berimbau como algo importante, bem como uso cultural de bens naturais como elemento emergente dessa interação, já que a produção do berimbau demanda a apropriação de bens naturais, sendo destaque a necessidade de cuidados com a espécie biriba (Eschweilera ovata (Cambess.) Mart. ex Miers).

Concluído o processo de inventário, em 2008 a Capoeira foi registrada como Patrimônio Cultural Imaterial do Brasil, sendo a Roda de Capoeira e o Ofício dos Mestres de Capoeira inscritos no Livro de Registro das Formas de Expressão e no Livro de Registro dos Saberes, respectivamente.

Findo o inventário e registro, ações que de acordo com as diretrizes do IPHAN são essenciais para salvaguarda dos patrimônios culturais materiais, fez-se necessário elaborar o Plano de Salvaguarda, 
uma vez que o inventário apenas aponta recomendações de salvaguarda, mas não detalha ações.

O plano de salvaguarda em âmbito nacional não foi definido e nem implantado. Entre os anos de 2008 e 2012 algumas ações foram realizadas com esse fim, como: criação do Grupo de Trabalho Pró-Capoeira (GTPC), Cadastro Nacional da Capoeira, e Prêmio Viva Meu Mestre, mas nenhum Plano de Salvaguarda foi efetivamente definido e elaborado em nível nacional.

No ano 2012, o IPHAN descentralizou as ações de salvaguarda e as superintendências regionais da instituição ficaram responsáveis pela elaboração e execução de ações locais junto aos capoeiristas e, desta forma, optou-se pela elaboração de Planos de Salvaguarda regionais. Por não ser possível conhecer quais estados concluíram seus planos, uma vez que essa informação ainda não é pública, o presente artigo aprofunda a questão da materialidade na salvaguarda da Roda de Capoeira em relação ao Plano de Salvaguarda do estado da Bahia, publicado em 2018. Esse plano foi elaborado por meio das discussões geradas no Ciclo de Seminários "Salve a Capoeira: Construção do Plano de Salvaguarda e do Conselho Gestor da Capoeira na Bahia", ocorrido entre os anos de 2013 e 2016.

$\mathrm{Na}$ construção desse plano, acompanhada pela autora, a importância da materialidade da capoeira para salvaguarda da expressão cultural - observada no inventário do bem cultural sob a recomendação "plano de manejo da biriba e outros recursos", foi debatida e ratificada no âmbito do grupo de trabalho (GT) intitulado "Fomento, sustentabilidade e internacionalização". Esse grupo ampliou essa recomendação e estabeleceu como uma diretriz do Plano de Salvaguarda "Desenvolver um plano de manejo para os recursos naturais utilizados na fabricação de instrumentos da roda de capoeira, que contemple a realização de pesquisas, sistemas coletivos de replantio e extrativismo sustentável" (IPHAN, 2016; ADINOLFI, 2018).

Essa ampliação extrapola a questão do berimbau e inclui os "instrumentos da roda de capoeira", o que destaca ainda mais a base material de suporte do bem imaterial como importante para sua salvaguarda. A diretriz também segue relacionando a temática ambiental como elemento emergente da base material suporte da capoeira quando aponta "plano de manejo para os recursos naturais" e “extrativismo sustentável”.

Especificamente em relação à sustentabilidade do berimbau, no Plano de Salvaguarda da Capoeira na Bahia os capoeiristas seguem afirmando a i) biriba como principal espécie utilizada na produção do instrumento, ii) o processo de extrativismo como principal meio de obtenção da espécie, 
iii) e sua escassez como uma realidade. Assim, está posto não apenas o tema do uso cultural de bens naturais para produção dos instrumentos musicais utilizados na Roda de Capoeira, mas a problemática de que se há recursos específicos para produção dos instrumentos utilizados na prática cultural, e se esses recursos estão escassos, os capoeiristas precisam ter garantido o direito ao uso cultural desses recursos para manterem a prática cultural.

A preocupação com a sustentabilidade do berimbau e outros instrumentos musicais foi colocada ainda na fase pré-inventário pelos detentores culturais, e perdurou ao longo de todo processo construtivo do plano de salvaguarda da Capoeira no estado da Bahia, fato que demonstra a importância dos instrumentos como a base de sustentação do bem imaterial e, consequentemente, a importância da manutenção dessa base na salvaguarda da expressão cultural.

No entanto, até o presente momento, nenhuma ação relacionada à manutenção da base material da Roda de Capoeira foi posta em prática quando consideramos que não há nenhum direcionamento estabelecido em relação ao uso cultural da espécie biriba ou outras espécies identificadas como relevantes para produção dos instrumentos utilizados na Roda de Capoeira. Disso decorre que os bens naturais utilizados, com destaque para a biriba, seguem em possível condição de escassez, o que infere no seu uso cultural para produção dos instrumentos utilizados na Roda de Capoeira, e no risco de salvaguarda da expressão cultural que sem esses "objetos musicais" pode "perder o sentido" e alterar os elementos que elevaram a expressão cultural à condição de patrimônio cultural imaterial.

\section{Considerações finais}

No âmbito da cultura e dos Patrimônios Culturais é impossível separar os aspectos materiais e imateriais, pois ambos formam uma unidade complexa e indissolúvel. Os saberes e fazeres só se efetivam mediante sustentação em elementos materiais. Desta maneira, a salvaguarda dos Patrimônios Culturais Imateriais, demanda que os aspectos tangíveis dos bens intangíveis sejam também considerados, principalmente aqueles que compõem a base de sustentação desses patrimônios, bem como os elementos emergentes dessa interação.

A análise da salvaguarda da Roda de Capoeira como patrimônio cultural imaterial ativado, demonstra que sua base material foi identificada como relevante pelos detentores culturais e considerada pelo IPHAN, que no inventário recomendou como medida de salvaguarda a atenção em relação ao berimbau e a biriba (Eschweilera 
ovata (Cambess.) Mart. ex Miers) principal recurso utilizado na produção do instrumento. Essa recomendação revelou a temática ambiental com emergente da relação entre materialidade $\mathrm{e}$ imaterialidade, sendo mais um componente a ser considerado na salvaguarda da expressão cultural.

O Plano de Salvaguarda da Capoeira na Bahia deu seguimento a essa recomendação e ampliou a diretriz de salvaguarda voltada a base material da Roda de Capoeira ressaltando não só o berimbau e a biriba como importantes, mas também os outros instrumentos utilizados na Roda de Capoeira e os bens naturais a eles relacionados. No entanto, desde que o plano foi finalizado, nenhuma ação foi executada e a importância da base material para salvaguarda do bem imaterial está ainda sob o aspecto retórico, pois segue sem atenção do IPHAN, o que pode colocar em risco a salvaguarda desse patrimônio cultural.

No âmbito da salvaguarda da Roda de Capoeira na Bahia, há necessidade de se avaliar quais são os recursos utilizados na produção dos instrumentos musicais aplicados na Roda de Capoeira e, especialmente em relação ao berimbau, identificar os bens naturais alternativos à biriba (Eschweilera ovata (Cambess.) Mart. ex Miers). Também é preciso conhecer a condição ecológica da espécie e avaliar se a mesma encontra-se sob risco. Essas ações também podem ser executadas na elaboração dos Planos de Salvaguarda das demais regiões do país.

Também é necessário que o IPHAN inicie uma articulação com os órgãos ambientais para debater sobre o uso cultural dos bens naturais utilizados na produção dos instrumentos musicais da Roda de Capoeira e chama-los a participar da construção das ações de salvaguarda. É necessário que haja compatibilidade entre políticas culturais e ambientais em torno da sustentabilidade desses dois elementos e da garantia do direto dos detentores culturais no uso de bens naturais relacionados à prática cultural. O uso cultural dos bens naturais relacionados à Roda de Capoeira precisa compor as ações de salvaguarda da expressão cultural e estar de acordo com a legislação ambiental e condição ecológica das espécies utilizadas na produção dos instrumentos.

No caso da biriba, principal espécie utilizada na produção do berimbau, que tem indicativo de escassez por parte dos detentores culturais; é necessário que os setores responsáveis pela gestão dos patrimônios culturais e do meio ambiente, juntamente com os capoeiristas, debatam sobre a regulamentação no uso e manejo da espécie, caso essa escassez se confirme.

A ativação patrimonial é uma 
decisão política, mesmo se tratando dos patrimônios culturais imateriais que demandam anuência dos detentores culturais. Se o Estado ativa um bem cultural como patrimônio, passa a ser responsável por sua proteção integral, o que inclui contemplar os aspectos intangíveis, tangíveis e os elementos emergentes dessa interação. No caso da Roda de Capoeira, a temática ambiental emergente necessita ser contemplada nas ações de salvaguarda no intuito de garantir o uso cultural dos bens naturais necessários à manutenção da base material de sustentação do bem imaterial.

\section{Referências bibliográficas}

ADINOLFI, Maria Paula Fernandes (org.). Plano de Salvaguarda da Capoeira na Bahia. Salvador: IPHAN. Bahia. 2018. Disponível em:

<http://portal.iphan.gov.br/uploads/publica cao/_planosalvaguardacapoeirabahia.pdf $>$. Acesso em 07 ago. 2020.

AREIAS, Almir das. O que é capoeira. 2. ed. São Paulo: Brasiliense, 1983.

BRASIL. Constituição (1988). Constituiçã o da República Federativa do Brasil. Brasília, DF: Senado Federal: Centro Gráfico, 1988.

FONSECA, Maria Cecília Londres. Referencias culturais: base para novas políticas de patrimônio. In: IPHAN. Manual de aplicação do INRC. Brasília: IPHAN, 2000.
GALLOIS, Dominique. Patrimônio cultural imaterial e povos indígenas. Iepé. 2006.

GEERTZ, Clifford. A interpretação das culturas. Rio de Janeiro: Ed. Guanabara. 1989.

INSTITUTO DO PATRIMÔNIO HISTÓRICO E ARTÍSTICO NACIONAL (IPHAN). Dossiê IPHAN 12 - Roda de Capoeira e Ofício dos Mestres de Capoeira. Brasília, 2014.

INSTITUTO DO PATRIMÔNIO HISTÓRICO E ARTÍSTICO NACIONAL (IPHAN). Os sambas, as rodas, os bumbas, os meus e os bois: princípios, ações e resultados da política de salvaguarda do patrimônio cultural imaterial do Brasil (2003 - 2010). Brasília, 2010.

INSTITUTO DO PATRIMÔNIO HISTÓRICO E ARTÍSTICO NACIONAL (IPHAN). Relatório do Seminário Estadual Salve a Capoeira.

Superintendência da Bahia. Bahia. 2016.

MENESES. José Newton Coelho. Modos de fazer e a materialidade da cultura "imaterial": o caso do queijo. Patrimônio e Memória, Assis, v.5, n.2, 2009, p.19-33.

RAYNAUT, Claude. Interdisciplinaridade: mundo contemporâneo, complexidade e desafios à produção e à aplicação de conhecimentos. In: PHILIPPI JR., Arlindo; FERNANDES, Valdir; ALVARENGA, Augusta Thereza de; PELICIONI, Maria Cecília Focesi. Práticas da Interdisciplinaridade no Ensino e Pesquisa. Barueri: Manole, 2015.

REGO, Waldeloir. Capoeira angola: ensaio sócioetnográfico. Salvador: Itapuã, 1968

SANT'ANNA, Marcia. A face imaterial do patrimônio cultural: os novos instrumentos de reconhecimento e valorização. 
Memória e patrimônio, Rio de Janeiro, 2003, p. 46-55.

TIEMBLO, María Pía Timon. Plan Nacional de Salvaguarda del Patrimonio Cultural Inmaterial. Atas do Colóquio Internacional "Políticas Públicas para o Património Imaterial na Europa do Sul: percursos, concretizações, perspectivas". Direção Geral do Patrimônio Cultural. Governo de Portugal. Portugal, $1^{a}$ edição, p. 71-85, 2013.

TOJI, Simone. Patrimônio imaterial: marcos, referências, políticas públicas e alguns dilemas. Patrimônio e Memória, Assis, v. 5, n. 2, 2009, p. 3-18.

UNESCO. Recomendação de Paris Convenção para a Salvaguarda do Patrimônio Cultural Imaterial, de 17 de outubro de 2003. Paris, 2003. Disponível em:

<http://unesdoc.unesco.org/images/0013/0 01325/132540por.pdf>. Acesso em: 20 agosto 2019. 